\title{
PENGARUH ELECTRONIC WORD OF MOUTH (E-WOM) DI INSTAGRAM TERHADAP DESTINATION IMAGE DI FARMHOUSE SUSU LEMBANG, BANDUNG
}

\author{
Miftakhul Noviyanti, Nungky Puspita, Riza Firmansyah \\ Fakultas Pariwisata, Universitas Pancasila Jakarta \\ Srengseng Sawah, Jagakarsa, Jakarta Selatan 12640, Indonesia
}

\begin{abstract}
Following the growth and evolution of the internet, electronic word of mouth have become an important phenomenon. The objective of this research is to analyze how the effect of electronic word of mouth (eWOM) in social media instagram toward destination image. This research applied quantitative approach. The sample of this research is 100 respondent who knew about Farmhouse Susu Lembang instagram account, collected using non-probability sampling. This research used questionnaire as research instrument and analyzed with multiple regression. The result of this research that the dimensions of negative feelings venting, concern for others, social benefits, and advice seeking from eWOM variables have significant influence, and the dimensions of platform assistance, expressing positive feelings, economic incentives, and helping the company from variables electronic word of mouth (eWOM) on Instagram social media has no significant effect on destination image.
\end{abstract}

Keywords: electronic word of mouth, social media, instagram, destination image

\section{PENDAHULUAN}

Kawasan Lembang merupakan salah satu lokasi wisata di Bandung yang paling sering dikunjungi oleh wisatawan. Lembang terletak di Kabupaten Bandung Barat yang terkenal sebagai salah satu kawasan dataran tinggi di Indonesia. Letak geografis yang terletak pada ketinggian antara 1.312 hingga 2.084 meter di atas permukaan laut membuat Lembang memiliki suhu rata-rata berkisar antara 17-27으. Kekayaan alam yang subur membuat Lembang memiliki pemandangan alam yang sangat indah. Suasana yang asri menjadikan wilayah Lembang sebagai tempat yang cocok dan dicari oleh orang-orang yang ingin berlibur.

Farmhouse Susu Lembang merupakan salah satu dari lima tempat wisata yang sedang trending di kawasan Lembang yaitu diantaranya: Dusun Bambu, Maribaya, Taman Begonia, dan Floating Market. Berlokasi tepat di pinggir jalan raya Lembang membuat para wisatawan dapat 
dengan mudah menemukan tempat wisata ini. Farmhouse Susu Lembang mulai dibuka pada tanggal 11 November 2015. Menurut hasil wawancara dengan Owner Farmhouse Susu Lembang Elen Tristrianto, Farmhouse Susu Lembang memang sengaja didisain seperti sebuah desa yang berada di pinggiran Eropa. Konsep pembangunan yang bertemakan nuansa Eropa memiliki tujuan untuk menarik minat wisatawan yang mendambakan dapat liburan ke Eropa. Dan yang membedakannya dengan obyek wisata lain adalah Farmhouse Susu Lembang memiliki sekitar 200 spot foto, dimana disetiap sudut bangunannya bisa dijadikan obyek foto. Selain bisa berfoto dengan latar belakang bangunan Eropa, wisatawan juga dapat mengunjungi Pating Zoo (bercengkrama dengan hewan) dan Rumah Hobbit. Ditengah ketatnya persaingan bisnis bidang pariwisata, obyek wisata ini tentu ingin mengenalkan produknya secara luas. Salah satunya melalui media internet.

Internet sebagai sarana komunikasi online telah menunjukkan perkembangan yang pesat. Hal ini dapat dilihat dari pemanfaatan dalam penggunaan internet itu sendiri. Saat ini internet tidak hanya digunakan untuk keperluan pribadi, namun internet juga dimanfaatkan para pemasar untuk melakukan kegiatan pemasarannya. Besarnya jumlah pengguna internet di Indonesia juga turut mendukung pertumbuhan pengguna media sosial. Hal ini dikarenakan media sosial merupakan salah satu media yang penggunaannya berbasis internet. Salah satu media sosial yang banyak digunakan untuk mendukung kegiatan pemasaran adalah Instagram. Ini terlihat dari pesatnya pertumbuhan pengguna sosial media Instagram.

Farmhouse Susu Lembang telah memiliki tiga akun resmi di beberapa media sosial diantaranya adalah Instagram, Facebook, dan Twitter. Akun-akun tersebut berisi tentang informasi wisata, unggahan foto-foto disetiap spot foto dan unggahan ulang dari wisatawan yang telah berkunjung ke Farmhouse dan membagikan foto serta komentarnya mengenai obyek wisata Farmhouse Susu Lembang. Namun akun media sosial Farmhouse yang masih aktif hingga saat ini hanyalah Instagram dengan user @farmhouselembangbdg, sedangkan akun-akun lainnya sudah tidak aktif melakukan pembaharuan seperti akun twitter dengan user @farmlembang terakhir aktif di tahun 2016, serta di akun facebook dengan nama Farmhouse Susu Lembang - BDG terakhir aktif pada bulan November 2017.

Akun

Instagram

@farmhouselembangbdg memiliki followers sebanyak 18 ribu orang dan masih akan terus bertambah seiring berjalannya waktu. Instagram Farmhouse dibuat dengan tujuan untuk memberikan informasi mengenai daya tarik wisata yang ditawarkan oleh Farmhouse Susu Lembang. Selain itu, akun Instagram @farmhouselembangbdg juga menjadi sarana atau media untuk memberikan komentar sebagai wadah dari electronic word of mouth mengenai produk dan atraksi wisata yang ditawarkan oleh Farmhouse Susu Lembang. 
Penelitian ini akan membahas mengenai sejauh mana electronic word of mouth di media sosial instagram memiliki pengaruh pada destination image di Farmhouse Susu Lembang, Bandung.

Gambar 1.1 Kerangka Pemikiran

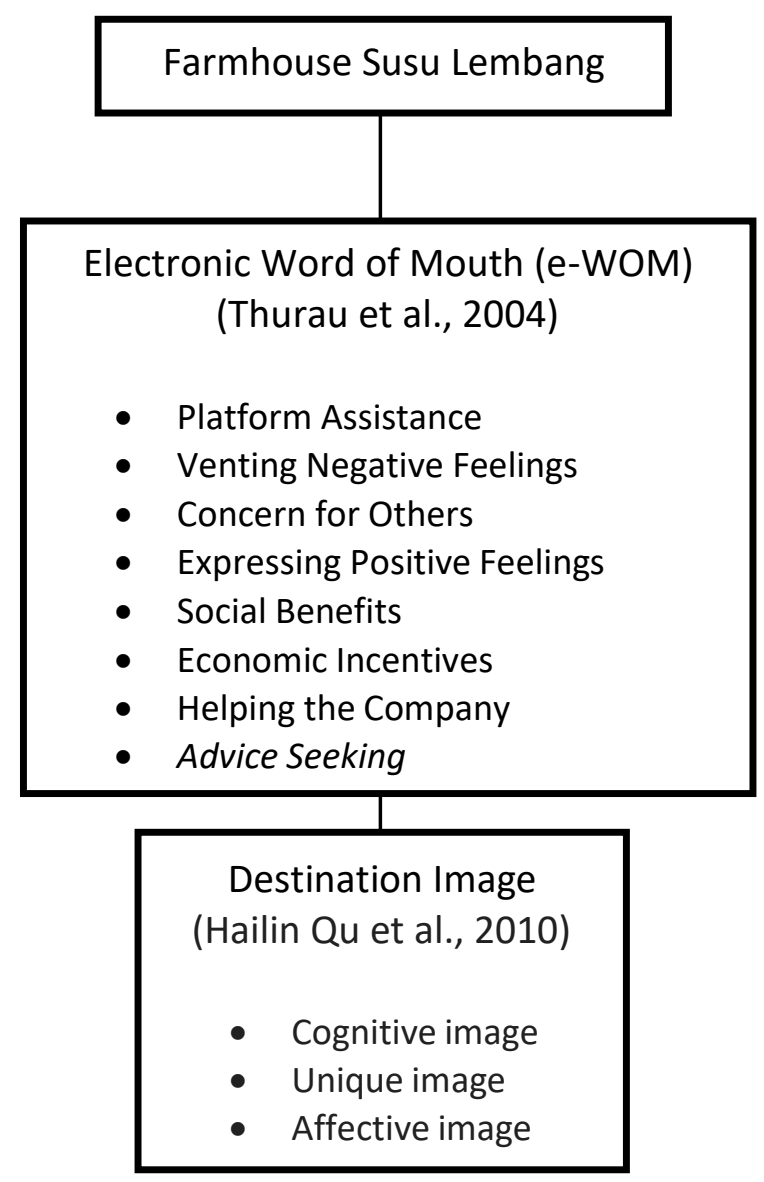

\section{HIPOTESA}

Terdapat delapan aspek dalam electronic word of mouth yaitu platform assistance, venting negative feelings, concern for others, expressing positive feelings, social benefits, economic incentives, helping the company dan advice seeking. Sehingga menimbulkan pengaruh terhadap destination image di Farmhouse Susu Lembang oleh karena itu hipotesis yang dipergunakan adalah:
1. Platform assistance merupakan kepercayaan konsumen terhadap platform yang digunakan. Ho1 = Platform assistance tidak berpengaruh secara secara signifikan terhadap destination image di Farmhouse Susu Lembang. $\mathrm{Ha1}=$ Platform assistance berpengaruh secara secara signifikan terhadap destination image di Farmhouse Susu Lembang. 
2. Venting negative feelings adalah keinginan untuk mencegah orang lain mengalami masalah yang mereka alami.

Ho2 = Venting negative feelings tidak berpengaruh secara signifikan terhadap destination image $\mathrm{di}$ Farmhouse Susu Lembang.

$\mathrm{Ha} 2$ = Venting negative feelings berpengaruh secara signifikan terhadap destination image $\mathrm{di}$ Farmhouse Susu Lembang.

3. Concern for others merupakan keinginan yang tulus untuk memberikan rekomendasi kepada konsumen lain.

Ho3 = Concern for others tidak berpengaruh secara secara signifikan terhadap destination image di Farmhouse Susu Lembang. $\mathrm{Ha} 3=$ Concern for others berpengaruh secara secara signifikan terhadap destination image di Farmhouse Susu Lembang.

4. Expressing positive feelings yaitu memiliki keinginan yang kuat untuk berbagi sukacita dari pengalaman positif dengan orang lain.

Ho4 = Expressing positive feelings tidak berpengaruh secara secara signifikan terhadap destination image di Farmhouse Susu Lembang. $\mathrm{Ha} 4=$ Expressing positive feelings berpengaruh secara secara signifikan terhadap destination image di Farmhouse Susu Lembang.

5. Social benefits merupakan keinginan untuk berbagi informasi dan berinteraksi dengan lingkungan sosial.

$\mathrm{Ho} 5=$ Social benefits tidak berpengaruh secara secara signifikan terhadap destination image di Farmhouse Susu Lembang.
Ha5 = Social benefits berpengaruh secara secara signifikan terhadap destination image di Farmhouse Susu Lembang.

6. Economics incentive merupakan keinginan untuk memperoleh insentif dari perusahaan.

Ho6 $=$ Economics incentive tidak berpengaruh secara secara signifikan terhadap destination image di Farmhouse Susu Lembang. Ha6 = Economics incentive berpengaruh secara secara signifikan terhadap destination image di Farmhouse Susu Lembang.

7. Helping the company merupakan keinginan konsumen untuk membantu perusahaan.

Ho7 = Helping the company tidak berpengaruhsecara secara signifikan terhadap destination image di Farmhouse Susu Lembang. Ha7 = Helping the company berpengaruhsecara secara signifikan terhadap destination image di Farmhouse Susu Lembang.

8. Advice seeking merupakan keinginan untuk mencari saran dan rekomendasi dari konsumen lain. Ho8 = Advice seeking tidak berpengaruh secara secara signifikan terhadap destination image di Farmhouse Susu Lembang. $\mathrm{Ha} 8=$ Advice seeking berpengaruh secara secara signifikan terhadap destination image di Farmhouse Susu Lembang.

\section{KEPUTUSAN}

Jika nilai Sig $>0,05$ maka Ho diterima Jika nilai Sig $<0,05$ maka Ha diterima

\section{METODE}


Penelitian ini bertujuan untuk menganalisis electronic word of mouth yang mempengaruhi destination image di Farmhouse Susu Lembang. Jenis penelitian yang digunakan dalam penelitian ini adalah penelitian kuantitatif dengan pendekatan deskriptif. Menurut Sugiyono (2013: 13), metode penelitian kuantitatif dapat diartikan sebagai metode penelitian yang berlandaskan pada filsafat positivisme, digunakan untuk meneliti pada populasi atau sampel tertentu, teknik pengambilan sampel pada umumnya dilakukan secara random, pengumpulan data menggunakan instrumen penelitian, analisis data bersifat kuantitatif/statistik dengan tujuan untuk menguji hipotesis yang telah di tetapkan.

Data yang digunakan dalam penelitian ini adalah data primer yaitu Sumber data yang didapatkan selain dari dokumen yang ada ialah melalui observasi secara langsung ke Farmhouse Susu Lembang, penyebaran kuesioner, serta wawancara kepada pengelola dan wisatawan yang mengunjungi Farmhouse Susu Lembang. Serta, dalam studi pustaka, penulis membaca literatur-literatur yang dapat menunjang penelitian, yaitu literaturliteratur yang berhubungan dengan penelitian ini.

Responden dalam penelitian ini berjumlah 100 orang yang berkunjung ke Farhouse Susu Lembang dan mengetahui akun instagram @farmhouselembangbdg.
Untuk teknik penentuan jumlah sampel dalam penelitian ini digunakan teknik nonprobability sampling. Menurut Sugiyono (2012), metode non-probability sampling merupakan teknik pengambilan sampel yang tidak memberikan peluang atau kesempatan yang sama bagi setiap unsur atau anggota populasi untuk dipilih menjadi sampel.

Sedangkan jenis teknik nonprobability sampling yang akan digunakan dalam penelitian ini adalah purposive sampling. Menurut Sugiyono (2016:85) purposive sampling adalah teknik pengambilan sampel sumber data dengan pertimbangan tertentu.

Skala yang digunakan untuk mengukur electronic word of mouth yang mempengaruhi destination image di Farmhouse Susu Lembang dalam kuesioner yaitu Skala Likert. Menurut Sugiyono (2010:93) Skala Likert digunakan untuk mengukur sikap, pendapat, dan presepsi seseorang atau sekelompok orang tentang fenomena sosial. Untuk setiap jawaban diberi skor, maka responden harus menggambarkan, mendukung pernyataan untuk digunakan jawaban yang dipilih.Skala Likert dalam penelitian ini terdiri dari Sangat Setuju (SS), Setuju (S), Tidak Setuju (TS), dan Sangat Tidak Setuju (STS). Adapun Untuk pengukuran variabel adalah sebagai berikut:

\begin{tabular}{|c|c|c|c|}
\hline Variabel & Sub Variabel & Indikator & Ukuran \\
\hline $\begin{array}{l}\text { Electronic } \\
\text { Word Of } \\
\text { Mouth (e- } \\
\text { WOM) }\end{array}$ & $\begin{array}{l}\text { a. Platform } \\
\text { assistance }\end{array}$ & $\begin{array}{l}\text { 1) Memudahkan word of mouth } \\
\text { mengenai daya tarik wisata } \\
\text { 2) Instagram adalah alat promosi } \\
\text { yang efektif }\end{array}$ & $\begin{array}{l}\text { Skala Likert } \\
1-4\end{array}$ \\
\hline
\end{tabular}




\begin{tabular}{|c|c|c|}
\hline $\begin{array}{l}\text { b. Venting } \\
\text { Negatives } \\
\text { Feelings }\end{array}$ & $\begin{array}{l}\text { Merasakan kesediaan orang lain } \\
\text { membagikan pengalaman yang tidak } \\
\text { menyenangkan dan mencegah } \\
\text { orang lain mengalami masalah yang } \\
\text { mereka alami. }\end{array}$ & $\begin{array}{l}\text { Skala Likert } \\
1-4\end{array}$ \\
\hline $\begin{array}{l}\text { c. Concern for } \\
\text { others } \\
\text { (kepedulian } \\
\text { terhadap } \\
\text { orang lain) }\end{array}$ & $\begin{array}{l}\text { 1) Mendapat rekomendasi daya } \\
\text { tarik wisata Farmhouse melalui } \\
\text { Instagram } \\
\text { 2) Memperoleh informasi lokasi } \\
\text { daya tarik wisata Farmhouse } \\
\text { melalui Instagram } \\
\text { 3) Mendapatkan informasi } \\
\text { keindahan dan keunggulan daya } \\
\text { tarik wisata Farmhouse melalui } \\
\text { Instagram }\end{array}$ & $\begin{array}{l}\text { Skala Likert } \\
1-4\end{array}$ \\
\hline $\begin{array}{l}\text { d. Expressing } \\
\text { Positive } \\
\text { Feelings }\end{array}$ & $\begin{array}{l}\text { 1) Merasakan kesenangan orang } \\
\text { lain di daya tarik wisata } \\
\text { Farmhouse melalui instagram } \\
\text { 2) Mendapatkan informasi } \\
\text { mengenai kelebihan daya tarik } \\
\text { wisata Farmhouse melalui } \\
\text { instagram } \\
\text { 3) Mendapatkan } \\
\text { pengalaman positif orang lain } \\
\text { terhadap daya tarik wisata } \\
\text { Farmhouse melalui Instagram }\end{array}$ & $\begin{array}{l}\text { Skala Likert } \\
1-4\end{array}$ \\
\hline $\begin{array}{l}\text { e. Social } \\
\text { Benefits }\end{array}$ & $\begin{array}{l}\text { Merasakan partisipasi orang lain } \\
\text { dalam berinteraksi di kolom } \\
\text { komentar akun Instagram } \\
\text { Farmhouse Susu Lembang yang } \\
\text { memungkinkan mereka menerima } \\
\text { keuntungan dari media electronic } \\
\text { word of mouth. }\end{array}$ & $\begin{array}{l}\text { Skala Likert } \\
1-4\end{array}$ \\
\hline $\begin{array}{l}\text { f. Economic } \\
\text { incentives }\end{array}$ & $\begin{array}{l}\text { Memperoleh insentif dari komunikasi } \\
\text { e-wom di akun Instagram Farmhouse } \\
\text { Susu Lembang }\end{array}$ & $\begin{array}{l}\text { Skala Likert } \\
1-4\end{array}$ \\
\hline
\end{tabular}




\begin{tabular}{|l|l|l|l|}
\hline \multirow{1}{*}{$\begin{array}{l}\text { g. Helping the } \\
\text { company } \\
\text { (membantu } \\
\text { perusahaan) }\end{array}$} & $\begin{array}{l}\text { Merasakan kesediaan orang lain } \\
\text { membantu publikasi daya tarik } \\
\text { wisata Farmhouse melalui instagram }\end{array}$ & $1-4$ \\
\cline { 2 - 5 } & $\begin{array}{l}\text { h. Advice } \\
\text { Seeking }\end{array}$ & $\begin{array}{l}\text { Mendapatkan rekomendasi serta } \\
\text { pengalaman dari orang lain } \\
\text { mengenai obyek wisata Farmhouse } \\
\text { Susu Lembang Skala Likert }\end{array}$ & $1-4$ \\
\hline $\begin{array}{l}\text { Destination } \\
\text { Image }\end{array}$ & $\begin{array}{l}\text { Menggambarkan dari kualitas pengalaman yang } \\
\text { didapat oleh wisatawan seperti suatu atraksi wisata, } \\
\text { lingkungan dan infrastruktur yang mendukung, serta } \\
\text { hiburan di obyek wisata Farmhouse Susu Lembang. }\end{array}$ & $1-4$ \\
& $\begin{array}{l}\text { Mengala Likert } \\
\text { wisata dan atraksi di Farmhouse Susu Lembang. }\end{array}$ & $1-4$ \\
\hline & $\begin{array}{l}\text { Menggambarkan perasaan yang menyenangkan, } \\
\text { membangkitkan suasana nyaman dan menarik ketika } \\
\text { dikunjungi. }\end{array}$ & $1-4$ \\
\hline
\end{tabular}

Uji validitas menyatakan bahwa instrumen yang digunakan untuk mendapatkan data dalam penelitian dapat digunakan atau tidak. Menurut Sugiyono (2012:121) menyatakan bahwa valid berarti instrumen tersebut dapat digunakan untuk mengukur apa yang seharusnya diukur. Syarat pengambilan keputusan uji validitas menurut Sugiyono (2012:133) yang harus dipenuhi yaitu harus memiliki kriteria sebagai berikut:

a. Jika p-value < alpha 0,05 maka item-item tersebut dinyatakan valid.

b. Jika p-value > alpha 0,05 maka item-item tersebut dinyatakan tidak valid.

Uji reliabilitas menyatakan bahwa apabila instrument yang digunakan beberapa kali untuk mengukur objek yang sama akan menghasilkan data yang sama. Menurut Sugiyono (2012:122) reliabilitas adalah derajat konsistensi/ keajengan data dalam interval waktu tertentu. Berdasarkan pengertian diatas maka reabilitas dapat dikemukakan sebagai suatu karakteristik terkait dengan keakuratan, ketelitian, dan kekonsistenan. Adapun kriteria untuk menilai reliabilitas instrumen penelitian ini yaitu suatu konstruk atau variabel dikatakan reliabel jika memberikan nilai Cronbach Alpha > 0,60.

\section{HASIL PEMBAHASAN}

Berdasarkan pengolahan dengan Analisis Regresi Linier Berganda dengan bantuan SPSS 15.0 maka terlihat beberapa hal sebagai berikut: 
Model Summary

\begin{tabular}{|l|l|r|r|r|}
\hline Model & $\mathrm{R}$ & $\mathrm{R}$ Square & \multicolumn{1}{c|}{$\begin{array}{c}\text { Adjusted R } \\
\text { Square }\end{array}$} & $\begin{array}{c}\text { Std. Error of the } \\
\text { Estimate }\end{array}$ \\
\hline 1 & $.492(\mathrm{a})$ & .242 & .175 & .612 \\
\hline
\end{tabular}

Koefisien determinan $\left(R^{2}\right)$ adalah 0,242 atau $24,2 \%$, maka selanjutnya dapat diambil kesimpulan bahwa variabel Platform assistance (X1), Venting negative feelings (X2), Concern for others (X3), Expressing positive feelings (X4), Social benefits (X5), Economic insentives (X6), Helping the company (X7), Advice seeking
(X8) dalam electronic word of mouth (eWOM) di media sosial instagram Farmhouse Susu Lembang tidak memiliki pengaruh yang cukup besar yaitu hanya sebesar 24,2\% terhadap destination image, sedangkan sisanya 75,8\% dipengaruhi oleh faktor-faktor lain diluar variabel $(X)$ yang tidak masuk dalam model penelitian.

ANOVA(b)

\begin{tabular}{|c|c|c|c|c|c|c|}
\hline & & $\begin{array}{l}\text { Sum of } \\
\text { Squares }\end{array}$ & Df & Mean Square & $\mathrm{F}$ & Sig. \\
\hline \multirow[t]{3}{*}{1} & Regression & 10.857 & 8 & \multirow{3}{*}{$\begin{array}{r}1.357 \\
.374\end{array}$} & \multirow[t]{3}{*}{3.627} & \multirow[t]{3}{*}{$.001(a)$} \\
\hline & Residual & 34.053 & 91 & & & \\
\hline & Total & 44.910 & 99 & & & \\
\hline
\end{tabular}

Hasil pengujian hipotesis secara simultan dengan menggunakan SPSS 15.0 untuk menguji pengaruh secara bersamasama memiliki estimasi $F$ sebesar 3.627 dengan nilai signifikan sebesar 0.001 (sangat kecil) lebih kecil dari 0,05 maka dapat dinyatakan $\mathrm{Ho}$ ditolak dan $\mathrm{Ha}$ diterima. Hal ini bahwa secara keseluruhan variabel independen dalam penelitian ini yaitu Platform assistance (X1), Venting negative feelings (X2), Concern for others (X3), Expressing positive feelings (X4), Social benefits (X5), Economic insentives (X6), Helping the company (X7), Advice seeking (X8) terhadap variabel terikat yaitu destination image secara bersama-sama berpengaruh secara simultan yang dapat digunakan terhadap electronic word of mouth (eWOM) di media sosial instagram Farmhouse Susu Lembang.

Coefficients(a)

\begin{tabular}{|l|c|c|c|c|}
\hline Model & $\begin{array}{c}\text { Unstandardized } \\
\text { Coefficients }\end{array}$ & $\begin{array}{c}\text { Standardized } \\
\text { Coefficients }\end{array}$ & $\mathrm{t}$ & Sig. \\
\hline
\end{tabular}




\begin{tabular}{|ll|r|r|r|r|r|}
\cline { 2 - 6 } & \multicolumn{1}{c|}{ B } & Std. Error & Beta & \multicolumn{1}{c|}{ B } & Std. Error \\
\hline 1 & 9.983 & 1.114 & & 8.962 & .000 \\
& (Constant) & -.047 & .057 & -.048 & -.828 & .408 \\
& PlatformAssistance & -.203 & .052 & -.238 & -3.874 & .000 \\
VentingNegativeFeelings & .239 & .043 & .288 & 5.601 & .000 \\
ConcernForOthers & .039 & .063 & .036 & .616 & .538 \\
Express.PositiveFeelings & .172 & .069 & .152 & 2.476 & .014 \\
SocialBenefit & .013 & .063 & .012 & .212 & .832 \\
Eco.Insentives & .001 & .056 & .000 & .009 & .993 \\
Help. TheCompany & -.320 & .063 & -.303 & -5.087 & .000 \\
AdviceSeeking & & &
\end{tabular}

\section{Keterangan}

Jika Sig > 0,05 maka tidak berpengaruh signifikan, Ho diterima dan Ha ditolak. Jika Sig < 0,05 maka berpengaruh signifikan, Ha diterima dan Ho ditolak.

\section{Hipotesa 1}

Ho1 = Platform assistance tidak berpengaruh secara secara signifikan terhadap destination image di Farmhouse Susu Lembang.

$\mathrm{Ha} 1=$ Platform assistance berpengaruh secara secara signifikan terhadap destination image di Farmhouse Susu Lembang. Platform assistance tidak berpengaruh signifikan terhadap destination image karena di dalam electronic word of mouth pemanfaatan media sosial di instagram lebih berfokus kepada pengguna instagram itu sendiri, seperti pertanyaan-pertanyaan mengenai informasi Farmhouse yang lebih mendominasi dari jumlah komentar yang ada. Selain itu, ketersediaan platform yang hanya ada di instagram juga membuat kegiatan word of mouth di media sosial menjadi terbatas.

\section{Hipotesa 2}

$\mathrm{Ho} 2=$ Venting negative feelings tidak berpengaruh secara signifikan terhadap destination image di Farmhouse Susu Lembang.

$\mathrm{Ha} 2=$ Venting negative feelings berpengaruh secara signifikan terhadap destination image di Farmhouse Susu Lembang.

Venting negative feelings berpengaruh signifikan terhadap destination image di Farmhouse Susu Lembang, karena pernyataan negative tersebut dapat memberikan gambaran dari konsumen yang menuliskan pengalaman tidak menyenangkannya dikolom komentar yang dapat dilihat oleh konsumen lain yang belum pernah berkunjung ke Farmhouse Susu Lembang.

\section{Hipotesa 3}

Ho3 = Concern for others tidak berpengaruh secara secara signifikan terhadap destination image di Farmhouse Susu Lembang. Ha3 = Concern for others berpengaruh secara secara signifikan terhadap destination image di Farmhouse Susu Lembang. Concern for others berpengaruh signifikan terhadap destination image di Farmhouse Susu Lembang karena Concern for others dapat membangun motivasi untuk 
wisatawan yang membaca ulasan dikolom komentar tentang rekomendasi obyek wisata dan informasi mengenai Farmhouse Susu Lembang, yang akan membentuk citra baik bagi Farmhouse Susu Lembang.

\section{Hipotesa 4}

Ho4 = Expressing positive feelings

tidak berpengaruh secara secara signifikan terhadap destination image di Farmhouse Susu Lembang. $\mathrm{Ha} 4=$ Expressing positive feelings berpengaruh secara secara signifikan terhadap destination image di Farmhouse Susu Lembang. Expressing positive feelings tidak berpengaruh signifikan terhadap destination image di Farmhouse Susu Lembang, karena komentar positive tidak terlalu mendominasi dari jumlah komentar-komentar yang ada, melainkan pertanyaanpertanyaan terkait informasi mengenai obyek wisata Farmhouse Susu Lembang.

5. Hipotesa 5

$\mathrm{Ho} 5=$ Social benefits tidak berpengaruh secara secara signifikan terhadap destination image di Farmhouse Susu Lembang. $\mathrm{Ha} 5$ = Social benefits berpengaruh secara secara signifikan terhadap destination image di Farmhouse Susu Lembang.

Social benefits berpengaruh signifikan terhadap destination image di Farmhouse Susu Lembang, karena dalam komunikasi ewom di instagram, pengguna dapat menerima keuntungan atau manfaat pada saat mereka mendapatkan informasi yang dicari, semakin banyak pengguna yang berpartisipasi artinya akan lebih banyak pendapat tentang obyek wisata Farmhouse Susu Lembang baik ulasan baik maupun buruk, yang dapat mempengaruhi citra dari destinasi itu sendiri.

\section{Hipotesa 6}

Ho6 = Economics incentive tidak berpengaruh secara secara signifikan terhadap destination image di Farmhouse Susu Lembang. Ha6 = Economics incentive berpengaruh secara secara signifikan terhadap destination image di Farmhouse Susu Lembang. Economic incentives tidak berpengaruh signifikan terhadap destination image di Farmhouse Susu Lembang, karena pada akun instagram @farmhouselembangbdg lebih cenderung mengarah kepada penerimaan manfaat untuk si pengguna itu sendiri, pengguna akan merasa bahwa melalui instagram mereka dapat mencari informasi melalui kolom komentar saja tanpa harus datang langsung ke Farmhouse Susu Lembang, sehingga manfaat ekonomi yang didapatkan tidak berpengaruh kepada citra destinasi Farmhouse Susu Lembang itu sendiri.

\section{Hipotesa 7}

Ho7 = Helping the company tidak berpengaruh secara secara signifikan terhadap destination image di Farmhouse Susu Lembang. Ha7 = Helping the company berpengaruh secara secara signifikan terhadap destination image di Farmhouse Susu Lembang. Helping the company tidak berpengaruh signifikan terhadap destination image di Farmhouse 
Susu Lembang, karena wisatawan yang membagikan konten informasi wisata melalui pendapat, opini, masukan atau sarannya tidak pernah atau tidak dapat bertatap muka secara langsung yang hanya terbatas pada memberikan dan membalas komentar saja sehingga hal tersebut dianggap kurang mempengaruhi helping the company electronic word of mouth pada media sosial instagram terhadap destination image.

\section{Hipotesa 8}

$\mathrm{Ho} 8=$ Advice seeking tidak berpengaruh secara secara signifikan terhadap destination image di Farmhouse Susu Lembang. $\mathrm{Ha} 8$ = Advice seeking berpengaruh secara secara signifikan terhadap destination image di Farmhouse Susu Lembang.

Advice seeking berpengaruh signifikan terhadap destination image di Farmhouse Susu Lembang, karena bahwa dengan mencari saran dan rekomendasi melalui media sosial instagram calon wisatawan akan mendapatkan gambaran terhadap produk/layanan pada destinasi wisata maka hal tersebut dinilai cukup membantu dan memotivasi calon wisatawan dalam keputusan memilih destinasi wisata.

\section{KESIMPULAN}

Pada aspek cognitive image, unique image, dan affective image dalam destination image didapatkan bahwa Farmhouse Susu Lembang memiliki cognitive image seperti lingkungan, infrastruktur dan keragaman wisata yang dapat memberikan pengalaman berkualitas bagi wisatawan. Unique image seperti kemenarikan wisata seperti wisata ala Eropa dan kemenarikan atraksi seperti Rumah Hobbit dan Mini Zoo. Serta affective image seperti perasaan nyaman ketika berkunjung karena memiliki fasilitas yang lengkap seperti toilet umum, tempat sampah, dan restoran.

Secara simultan, kedelapan variabel electronic word of mouth berpengaruh secara bersama-sama terhadap destination image. Sedangkan secara parsial, empat dari delapan variabel destination image yaitu venting negative feelings, concern for others, social benefits dan advice seeking berpengaruh signifikan terhadap destination image di Farmhouse Susu Lembang. Sedangkan empat lainnya yaitu platform assistance, expressing positive feelings, economic incentives, dan helping the company pada media sosial Instagram tidak berpengaruh signifikan terhadap destination image di Farmhouse Susu Lembang.

\section{DAFTAR PUSTAKA}

APJII (Asosiasi Penyelenggara Jasa Internet Indonesia) [Internet] [diakses pada 2018Maret23] Tersedia pada: https://www.apjii.or.id.

Albarq, A.N. 2014. Measuring the Impacts of Online Word of Mouth on Tourists' Attitude and Intentions to Visit Jordan: An Empirical Study [Journal]. Published by Canadian Center of Science and Education.

Arian, F. 2015. Pembentukan Keputusan Pembelian Melalui Word of Mouth, 
Country of Origin, Desain Dan Fitur Produk (Studi Pada Produk Smartphone Oppo) [SKRIPSI]. Lampung (ID): Fakultas IImu Sosial Dan IImu Politik Universitas Lampung.

Arisandi, N.G.A.D.P. 2015. Citra Pariwisata Bali Dalam Situs Jejaring Sosial [Doctoral Thesis] Bali (ID): Universitas Udayana.

Farida, N. 2013. Pengaruh Kualitas Layanan, Fasilitas Wisata, Promosi Terhadap Citra Destinasi Dan Niat Berperilaku Pada Obyek Wisata Karimunjawa Kabupaten Jepara. Jurnal Administrasi Bisnis FISIP Universitas Diponegoro, Vol. 31.

Ghozali, I. 2012. Aplikasi Analisis Multivariate dengan Program IBM SPSS. Yogyakarta (ID): Universitas Diponegoro.

Goyette, I., Richard, L., Bergeron, J. dan Marticotte, F. 2010. e-WOM Scale: Word-of-Mouth Measurement Scale for e-Services Context. Journal of Administrative Sciences, 27 pp. 5-23.

Ismayanti. 2010. Pengantar Pariwisata. Jakarta (ID): PT Grasindo.

Jeong, E. dan Jang, S. 2011. Restaurant Experiences Triggering Positive Electronic Word-Of-Mouth (Ewom)
Motivations [Journal]. International Journal of Hospitality Management. Elsevier.

Jalilvand, M., R., dan Samiei, N. 2012. The Effect of E-WOM on Brand Image and Purchase Intention. Journal of Marketing Intelligence and Planning, Vol 30/No 4, 460-476. Emerald.

Kompas.com. 2014. Pertumbuhan Pengguna Instagram Paling Pesat [Internet] [diunduh2018Maret23]

Tersedia pada:

https://tekno.kompas.com/read/ 2014/01/26/1404307/Pertumbuhan.P engguna.Instagram.Paling.Pesat.

Kotler, P., dan A.B. Susanto. 2000. Manajemen Pemasaran di Indonesia: Analisis Perencanaan, Implementasi, dan Pengendalian. Jakarta (ID): Salemba Empat.

Kotler, P. 2004. Manajemen Pemasaran: Analisis, Perencanaan, implementasi dan Kontrol, Edisi 11. Alih Bahasa, Hendra Teguh. Jakarta (ID): PT. Prenhalindo.

Kotler, P. \& Keller, K. L. 2012. Marketing Management. Global Edition 4e. London (IN): Pearson Education Limited 2012. 
Lopes, S.D.F. 2011. "Destination Image: Origins, Developments and Implications" [Journal]. Revista de Turismo y Patrimonio Cultural, 307311.

Marzuki. 2005. Metodologi Riset Panduan Penelitian. Yogyakarta (ID): Ekosiana.

Morissan. 2007. Periklanan : Komunikasi Pemasaran Terpadu. Jakarta (ID): Ramdina Prakarsa.

Paludi, S. 2016. Analisis Pengaruh Electronic Word of Mouth (e-WOM) Terhadap Citra Destinasi, Kepuasan Wisatawan, Dan Loyalitas Destinasi Perkampungan Budaya Betawi (PBB) Setu Babakan Jakarta Selatan. [Tesis] Jakarta (ID): MM IBN Jakarta.

Priyatno, D. 2009. SPSS untuk Analisis Korelasi, Regresi, dan Multivariate. Yogyakarta (ID): Gava Media.

Qu. H., Kim, Hyunjung. L., Im, Hyunjung. H. 2010. A model of destination branding: Integrated the concepts of the branding and destination image. Journal of Tourism Management 32: 465-476.

Riantika, I. 2016. Pengaruh Electronic Word of Mouth, Daya Tarik, dan Lokasi Terhadap Keputusan Berkunjung Wisatawan di Curug Sidoharjo [SKRIPSI]. Yogyakarta (ID): Fakultas Ekonomi Universitas Sanata Dharma.
Sari, V.M. 2012. Pengaruh Electronic Word of Mouth (eWOM) Di Social Media Twitter Terhadap Minat Beli Konsumen (Studi Pada Restoran Holycowsteak) [SKRIPSI]. Depok (ID): Fakultas IImu Sosial dan IImu Politik Universitas Indonesia.

Setiawan, P.Y., et.al. 2014. The Effect of eWom on Destination Image, Satisfaction and Loyalty. Intrenational Journal of Business and Managenet Invention. Vol.3 Issue 1. PP.22-99.

Sugiyono. 2003. Metode Penelitian Bisnis. Cetakan Kelima: Penerbit CV. Bandung (ID): Alfabeta.

Sugiyono. 2012. Metode Penelitian Bisnis. Bandung (ID): CV Alfabeta.

Sugiyono. 2013. Metode Penelitian Pendidikan (Pendekatan Kuantitatif, Kualitatif dan R\&D. Bandung (ID): CV Alfabeta.

Thurau, H. T., Gwinner, K.P., Walsh, G. dan Gremler, D.D. 2004. Electronic Wordof-Mouth Via Customer-Opinion Platforms: What Motivates Consumer to Articulate Themselves on the Internet. Journal of Interactive Marketing, Vol 18/No 1, 38-5 
